\title{
Cannabinoid hyperemesis syndrome presentation to the emergency department: A two-year multicentre retrospective chart review in a major urban area
}

\author{
Jeremy M. Hernandez, MD, $\mathrm{PhD}^{*}$; Jared Paty, $\mathrm{BHSc}^{\mathrm{MSc}}{ }^{\dagger}$; Ira M. Price, $\mathrm{MD}^{*}$
}

\section{ABSTRACT}

Objective: Cannabinoid hyperemesis syndrome (CHS) is a paradoxical side effect of cannabis use. Patients with $\mathrm{CHS}$ often present multiple times to the emergency department (ED) with cyclical nausea, vomiting, and abdominal pain, and are discharged with various misdiagnoses. CHS studies to date are limited to case series. The objective was to examine the epidemiology of $\mathrm{CHS}$ cases presenting to two major urban tertiary care centre EDs and one urgent care centre over a 2-year period.

Methods: Using explicit variables, trained abstractors, and standardized abstraction forms, we abstracted data for all adults (ages 18 to 55 years) with a presenting complaint of vomiting and/or a discharge diagnosis of vomiting and/or cyclical vomiting, during a 2-year period. The inter-rater agreement was measured using a kappa statistic.

Results: We identified 494 cases: mean age $31(+/-11)$ years; $36 \%$ male; and $19.4 \%$ of charts specifically reported cannabis use. Among the regular cannabis users ( $>$ three times per week), $43 \%$ had repeat ED visits for similar complaints. Moreover, of these patients, $92 \%$ had bloodwork done in the ED, 92\% received intravenous fluids, $89 \%$ received antiemetics, $27 \%$ received opiates, $19 \%$ underwent imaging, $8 \%$ were admitted to hospital, and $8 \%$ were referred to the gastroenterology service. The inter-rater reliability for data abstraction was kappa $=1$.

Conclusions: This study suggests that $\mathrm{CHS}$ may be an overlooked diagnosis for nausea and vomiting, a factor that can possibly contribute to unnecessary investigations and treatment in the ED. Additionally, this indicates a lack of screening for CHS on ED history, especially in quantifying cannabis use and eliciting associated symptoms of CHS.

\section{RÉSUMÉ}

Objectif: Le syndrome de I'hyperémèse cannabique (SHC) est un effet indésirable paradoxal de I'utilisation du cannabis. Les patients souffrant du syndrome consultent souvent au service des urgences (SU) pour des nausées et des vomissements récurrents, accompagnés de douleurs abdominales, et font l'objet de divers diagnostics erronés inscrits au registre de sortie. Les études sur le SHC ne portent actuellement que sur des séries de cas. Aussi était-il de notre intention d'examiner l'épidémiologie des cas de SHC dans deux SU rattachés à un grand centre de soins tertiaires, situé en milieu urbain, ainsi que dans un centre de soins d'urgence, sur une période de deux ans. Méthode: Nous avons procédé, à l'aide de variables clairement définies et de formulaires uniformes de résumé analytique ainsi qu'avec le soutien de rédacteurs de sommaires formés, au résumé des données concernant tous les adultes (18-55 ans) qui avaient pour principal motif de consultation des vomissements ou qui avaient fait l'objet d'un diagnostic de vomissements ou de vomissements récurrents, inscrit au registre de sortie, sur une période de deux ans. La fidélité interévaluateurs a été mesurée à l'aide du test de concordance kappa.

Résultats: Ont été relevés 494 cas : I'âge moyen était de 31 $(+/-11)$ ans, il y avait $36 \%$ d'hommes et une mention explicite de l'usage du cannabis figurait dans $19,4 \%$ des dossiers. Parmi les utilisateurs fréquents de cannabis ( $>3$ fois par semaine), $43 \%$ ont consulté plusieurs fois au SU pour des troubles similaires. De plus, $92 \%$ d'entre eux ont subi des analyses de sang au SU, $92 \%$ ont reçu des liquides par voie intraveineuse; $89 \%$, des antiémétiques; $27 \%$, des opiacés; $19 \%$ ont été soumis à des examens par imagerie, $8 \%$, hospitalisés et $8 \%$, dirigés vers des services de gastroentérologie. La fidélité interévaluateurs en ce qui concerne les résumés des données avait une valeur kappa de 1.

Conclusions: Les résultats de l'étude donnent à penser que le SHC est un diagnostic méconnu pour ce qui est des nausées et des vomissements, un facteur susceptible de jouer un rôle dans les demandes inutiles d'examens et de traitements au SU. En outre, les résultats sont révélateurs d'un manque de dépistage du SHC au moment de I'anamnèse au SU, surtout en ce qui a trait à la quantification de l'utilisation du cannabis et à l'apparition des symptômes associés au SHC.

Keywords: cannabis hyperemesis syndrome, cannabis, marijuana, hyperemesis, vomiting

From the *Division of Emergency Medicine, Department of Medicine; and the tDepartment of Family Medicine, McMaster University, Hamilton, ON.

Correspondence to: Dr. Jeremy M. Hernandez, Hamilton General Hospital, Division of Emergency Medicine (2nd Floor, Room 252), 237 Barton Street, East Hamilton, ON L8L 2X2; Email: jeremy.hernandez@medportal.ca 


\section{INTRODUCTION}

Cannabinoid hyperemesis syndrome (CHS) is a paradoxical side effect of cannabis use in which patients often present with cyclical nausea, vomiting, and abdominal pain with no other identifiable etiology, and subsequently are discharged with a variety of misdiagnoses. ${ }^{1}$ This phenomenon has been increasingly described in the literature; however, studies to date are limited to case reports and case series. ${ }^{2-9}$

Since the introduction of the Marijuana [sic] Medical Access Regulations (MMAR) in 2001, the use of medical cannabis among Canadians has steadily increased, from under 500 authorized individuals to over 30,000 today, despite a decline in prevalence of recreational use. ${ }^{10}$ Recently, the federal government sought to improve the program and create a new commercial industry with quality-controlled production by instituting new federal regulations in June 2013. With the new Marihuana for Medical Purposes Regulations (MMPR), the only legal source of cannabis is designated producers licensed by Health Canada. ${ }^{11-14}$ The Federal Government will once again be updating the MMPR in the coming months.

Cannabis has various therapeutic properties, including antiemesis, appetite stimulation, and pain control, which have led to cannabis use in patients with cachexia associated with acquired immunodeficiency syndrome (AIDS), chemotherapy-induced nausea and vomiting, painful peripheral neuropathy, and muscle spasticity due to multiple sclerosis. ${ }^{1,15-17}$ CHS is a cluster of symptoms characterized by cyclical nausea and vomiting with abdominal pain paradoxically induced by long-term or short-term cannabis use. ${ }^{18}$

The pathophysiology of CHS is not yet defined but is thought to be related to endocannabinoid dysregulation. ${ }^{15}$ Prior to the diagnosis of CHS, patients often suffer for years with potentially debilitating symptoms on a cyclical basis. These patients typically present multiple times to emergency departments (EDs) with similar symptoms and receive multiple diagnostic tests and invasive procedures without a clear diagnosis or treatment plan. ${ }^{18}$ Furthermore, CHS has been theorized to indirectly precipitate further sequelae such as acute renal failure. ${ }^{19}$ As such, it is important for ED physicians to consider CHS in the differential diagnosis of patients presenting with intractable cyclical vomiting plus abdominal pain, because this may reduce the need for costly and invasive testing.
Medical cannabis is an increasingly accepted and used therapeutic option in medicine. However, only case studies and case series articles have documented CHS in the literature. Using a retrospective medical records review study design, the objective of our study was to document the epidemiology of CHS cases presenting to two major urban tertiary care centre EDs and one urgent care centre in Hamilton, Ontario, over a 2-year period.

\section{METHODS}

We designed a retrospective chart review incorporating the key elements, as previously outlined. ${ }^{20-22}$ The study was undertaken at Hamilton Health Sciences, which provides emergency care to adult patients in the city of Hamilton through two EDs and one urgent care centre. All departments are staffed by full-time emergency physicians. All adult patients ages 18 to 55 years presenting to Hamilton EDs with a chief complaint of vomiting and/or a discharge diagnosis of vomiting and/ or cyclical vomiting were reviewed during a 2-year period between January 1, 2013 and December 31, 2014. An un-blinded researcher abstracted $100 \%$ of the cases, after which a second researcher independently abstracted a random selection of $20 \%$ of the selected cases. Both used study-specific data collection forms for this purpose with explicit variable definitions. Abstractor performance was monitored, and differences were planned for resolution by group consensus. Periodic meetings were also held to discuss any difficulties and to provide abstractor performance feedback. Inter-rater reliability on data abstraction was measured and tested using a Cohen's Kappa statistic.

The primary data abstracted from each chart included mention of drug use, specific mention of cannabis use and cannabis use greater than three times per week, and an alternate diagnosis made in the ED. The cut-off of cannabis use greater than three times per week was based on previous studies suggesting that the majority $(>75 \%)$ of cases occur in those using cannabis greater than three times per week. ${ }^{7,23}$ A consensus definition of "regular cannabis use" does not currently exist in the literature. Secondary data abstracted included whether the patient had repeat visits to the ED, received bloodwork, urine toxicology, imaging, intravenous (IV) fluids, opiates, or antiemetics in the ED, whether the patient was admitted, or whether the patient received referral for consultation from gastroenterology. 
Statistical analysis was carried out using a two-tailed Fisher exact test with GraphPad software (GraphPad Software Inc., La Jolla, CA). This research project was approved by the Hamilton Integrated Research Ethics Board (HiREB).

\section{RESULTS}

A total of 494 charts were identified over the 2-year study period, of which 101 patients left the ED before being seen by a physician, 9 were referrals admitted directly to a specialty service (thus not assessed in the ED), and 9 had missing chart data, yielding 375 charts for analysis, 323 of which were unique individuals. The mean age was 31 years (SD 11), 35.7\% of patients were male, and an alternate diagnosis was identified on 35 charts (Table 1). Alternate diagnoses included post-chemotherapy nausea and vomiting $(\mathrm{n}=13)$, side effects of metastatic cancer $(n=6)$, medication side effects $(n=4)$, acute alcohol withdrawal or intoxication $(\mathrm{n}=2)$, inflammatory bowel disease $(\mathrm{n}=2)$, gastroparesis $(n=1)$, viral hepatitis $(n=1)$, traveler's diarrhea $(n=1)$, dysmenorrhea $(n=1)$, bowel obstruction $(n=1)$, diabetic ketoacidosis $(n=1)$, pyelonephritis $(n=1)$, and cholecystitis $(\mathrm{n}=1)$.

Drug use was indicated in the chart of 99 patients (26.4\%), and cannabis was specifically indicated in 73 charts (19.4\%). Of those that indicated cannabis use, 39 $(10.4 \%)$ charts quantified the use of cannabis as greater than three times per week, 19 (5.1\%) charts specified cannabis use as less than three times a week, whereas 15 charts $(4.0 \%)$ showed no specific mention of frequency. There were two charts that identified patients using cannabis for medicinal purposes, and, in both cases, use

\begin{tabular}{|lcr|}
\hline Table 1. Patient demographics & & \\
\hline & $\mathrm{n}^{*}$ & $\%$ \\
\hline Total charts analysed & 375 & \\
Average age (SD) & $31.7(11.1)$ & \\
Males & 134 & 35.7 \\
Alternate dx & 35 & 9.3 \\
Drug use mentioned & 99 & 26.4 \\
Cannabis mentioned & 73 & 19.5 \\
Cannabis frequency NM & 15 & 4.0 \\
Cannabis <3 times per week & 19 & 5.1 \\
Cannabis >3 times per week & 39 & 10.4 \\
Alternate dx & 2 & 0.05 \\
\hline Dx=diagnosis; NM=not mentioned. & & \\
*Unless otherwise indicated. & & \\
\hline
\end{tabular}

\begin{tabular}{|c|c|c|c|c|c|}
\hline \multirow[b]{2}{*}{ Category } & \multicolumn{2}{|c|}{$\begin{array}{l}\text { Cannabis users } \\
\qquad(\mathrm{n}=37)\end{array}$} & \multicolumn{2}{|c|}{$\begin{array}{c}\text { Non-cannabis } \\
\text { users ( } n=336)\end{array}$} & \multirow{2}{*}{$\frac{\text { Difference }}{p \text {-value }}$} \\
\hline & $\mathrm{n}$ & $\%$ & $\mathrm{n}$ & $\%$ & \\
\hline Repeat visits* & 16 & 43.2 & 62 & 18.5 & 0.001 \\
\hline Bloodwork* & 34 & 91.9 & 255 & 75.9 & 0.035 \\
\hline Imaging & 7 & 18.9 & 83 & 24.7 & 0.545 \\
\hline Fluids* & 34 & 91.9 & 257 & 76.5 & 0.035 \\
\hline Opiates* & 10 & 27.0 & 37 & 11.0 & 0.015 \\
\hline Antiemetics & 33 & 89.2 & 279 & 83.0 & 0.482 \\
\hline Admitted & 3 & 8.1 & 42 & 12.5 & 0.598 \\
\hline Gl referral & 3 & 8.1 & 15 & 4.5 & 0.406 \\
\hline
\end{tabular}

was greater than three times per week. Of those with an alternate diagnosis, two were identified as cannabis users, and both had use greater than three times per week.

A post-hoc subgroup analysis was conducted on the group of $37(9.9 \%)$ regular cannabis users, identified as cannabis use of greater than three times per week with no alternate diagnosis (Table 2). Among those ED visits, $43 \%(n=16)$ were repeat visits (automatically flagged if presenting within 2 weeks of being discharged from the ED) compared to $18.5 \%(n=62)$ of visits among non-cannabis users $(p<0.001)$. Of the regular cannabis users, $92 \%(n=34)$ had bloodwork done in the ED compared to $76 \%(\mathrm{n}=255)$ of non-cannabis users $(p<0.05), 92 \%(\mathrm{n}=32)$ received IV fluids compared to $76.5 \%(\mathrm{n}=257)$ of non-cannabis users $(p<0.05)$, and $27 \%(n=10)$ received opiates compared to $11 \%$ of noncannabis users $(p<0.05)$. Furthermore, $89 \%(n=33)$ received antiemetics, $19 \%(\mathrm{n}=7)$ received some form of imaging, $8 \%(\mathrm{n}=3)$ were admitted to the hospital, and $8 \%(n=3)$ were referred to the gastrointestinal service. The pathognomonic finding of symptom resolution with hot showers was not documented in any charts reviewed.

\section{DISCUSSION}

In this manuscript, we have, to our knowledge, described the largest retrospective chart review of CHS cases published to date. We identified patients presenting to the ED with a chief complaint of vomiting and identified a documented history of cannabis use. Our findings are consistent with previously published case reports 


\begin{tabular}{ll|}
$\begin{array}{l}\text { Table 3. Clinical } \\
\text { syndrome }\end{array}$ & criteria for cannabinoid hyperemesis \\
\hline $\begin{array}{l}\text { Essential } \\
\text { criteria }\end{array}$ & Long-term cannabis use \\
\hline Major features & $\begin{array}{l}\text { Severe cyclical nausea and vomiting } \\
\text { Resolution with cannabis cessation }\end{array}$ \\
& $\begin{array}{l}\text { Relief with hot showers/baths } \\
\text { Abdominal pain, epigastric, or periumbilical }\end{array}$ \\
& Weekly cannabis use \\
Supportive & Age $<55$ years \\
features & Weight loss $>5$ kg \\
& Morning predominance of symptoms \\
& Normal bowel habits \\
& Negative laboratory, radiographic, and \\
endoscopic test results
\end{tabular}

and case series identifying cases of CHS, and we suggest that CHS is poorly screened, likely underdiagnosed, and results in a large number of investigations and repeat visits.

CHS was first described in a case series in $2004^{24}$ and has subsequently been described in a number of case reports and case series. ${ }^{5,7,25,26}$ Through a systematic review of case studies, a set of diagnostic criteria has been developed ${ }^{7}$ and further endorsed, ${ }^{27}$ which is outlined in Table 3. Of note, the essential criterion for making the diagnosis of CHS is chronic cannabis use, with a major feature being weekly cannabis use. Among the patients included in our review, only $26.4 \%$ had any mention of drug use charted, with cannabis use being specifically mentioned on only $19.4 \%$ of all reviewed charts. Therefore, it is clear that even among patients with vomiting without a clear etiology, there is a significant lack of screening for CHS. Even among a population that this study identified as potentially meeting criteria for CHS, clinicians are either failing to question patients' cannabis use, or failing to document it. This lack of screening is a main finding and contributes to the underdiagnosis of CHS.

As others have mentioned, ${ }^{7,26}$ the reasons for this lack of screening are likely multifactorial. Being a newly identified phenomenon, it is unlikely to be consistently considered on the differential diagnosis of these patients. Additional confusion arises from the diagnostic similarities with cyclical vomiting syndrome (CVS). Although severe cyclical nausea and vomiting are part of the diagnostic criteria for CHS, CVS is a separate clinical entity, classified as a functional gastrointestinal disorder, with its own diagnostic criteria (Rome III) ${ }^{28}$ CVS is a widely recognized disorder, and thus patients who have otherwise undifferentiated nausea and vomiting may often be given this diagnosis without further questioning into their substance use. Another factor contributing to the lack of screening is the attitudes surrounding cannabis use and its acceptance both culturally and legally. Our average patient population was 31.1 years old. These individuals often present to the ED with significant others or family members, making questioning around substance use either uncomfortable or unreliable. A recent study addressed this phenomenon, assessing the prevalence of cannabis use reported in the ED before and after cannabis legalization in Colorado, and found that patients were more likely to disclose cannabis use following legalization. ${ }^{26}$ Only two charts in our study identified legal, medicinal users of cannabis, and therefore it is assumed that the remainder were using cannabis for recreational purposes. Thus, although it is clear that screening for CHS is lacking, there are many issues that contribute to this.

Of the $19.4 \%(n=73)$ of patients in this study who were explicitly asked about cannabis use, greater than half $(53.4 \%, \mathrm{n}=37)$ stated that they used cannabis more than three times per week. Therefore, $10.4 \%$ of our study population used cannabis three or more times per week. This compares to the Canadian national average of $3.2 \%$ using cannabis once per week and $1.8 \%$ using cannabis daily. ${ }^{29}$ A subgroup analysis was carried out on this group of high-frequency cannabis users, because these were considered most likely correlated with a diagnosis of CHS. Consistent with other reports, we found that this population often had a high degree of repeat visits and a large number of negative investigations.

Although there was statistically no difference in the frequency of admission, imaging, or antiemetic administration between the two groups, a number of factors were more prevalent in the high-frequency cannabis group (see Table 2). Repeat visits, bloodwork, and fluid resuscitation were all more common among high-frequency users as compared to non-cannabis users. Additionally, frequent cannabis users received more opiates in the ED for abdominal pain management, despite the potential of narcotics to precipitate increased nausea. ${ }^{15}$ These data suggest that there is some increase in the frequency of investigations and repeat visits among high-frequency cannabis users with nausea and vomiting. If these patients had a diagnosis of CHS earlier, it is possible that excess testing would be somewhat reduced. 
This study found a high prevalence of antiemetic use, with $83.9 \%$ of all-comers receiving antiemetic therapy and $89.2 \%$ of cannabis users receiving antiemetics, despite evidence suggesting its futility in this population. ${ }^{15}$ It is not clear in our study how patients who received antiemetics responded. However, there is limited evidence to suggest that haloperidol may provide some antiemetic effect in CHS. ${ }^{30}$ An earlier recognition of CHS would potentially allow for earlier initiation of this targeted therapy.

Given the nature of a phenomenon that is relatively new to the literature and the retrospective study design, there are a number of limitations in this study. Firstly, CHS is a differential diagnosis that is not often contemplated by ED physicians, with a set of diagnostic criteria that are not commonly screened for. As such, there were minimal charted data regarding cannabis use and CHS diagnostic criteria, particularly in regard to the pathognomonic feature of symptom resolution with hot showers, limiting our ability to identify cases of CHS. A lack of documentation of these criteria unfortunately precludes the ability to calculate the number of patients who meet the diagnosis of CHS through a retrospective chart review.

Interestingly, the charts that we reviewed showed an unusually high prevalence of patients leaving without being seen (LWBS) by the ED physician. The goal LWBS rate is around $2 \%$ for all ED visits, and our review had a rate of $20 \%$ of charts screened. Although there was no clear cause for this, it is postulated that the population captured by our inclusion criteria was a generally young and otherwise healthy group who would have been triaged as low acuity. Wait times would have been increased for this population. Evidence suggests that ED patients triaged with low acuity and subsequently longer wait times have significantly higher LWBS rates. ${ }^{31}$ Thus, a key factor in our high LWBS rate was likely wait times. Unfortunately, it was not possible to directly investigate this using our study design.

\section{CONCLUSIONS}

This study adds to a growing body of research that suggests CHS may be an overlooked part of the differential diagnosis for vomiting, a factor that contributes to unnecessary investigations and treatments in the ED. There appears to be a lack of screening for the diagnostic criteria of CHS, especially in quantifying cannabis use history, and associated symptoms of the syndrome. This suggests the need for further investigation in regard to screening for CHS, and would benefit from a prospective study to better establish the prevalence of other signs and symptoms.

Competing interests: None declared.

\section{REFERENCES}

1. Sun S, Zimmermann AE. Cannabinoid hyperemesis syndrome. Hosp Pharm 2013;48(8):650-5.

2. Brenna O, Aasarod K, Gustafsson BI. A man in his 30s with recurrent vomiting and abdominal pain relieved by hot showers. Tidsskr Nor Laegeforen 2011;131(21):2134-6.

3. Felton D, Zitomersky N, Manzi S, et al. 13-year-old girl with recurrent, episodic, persistent vomiting: out of the pot and into the fire. Pediatrics 2015;135(4):e1060-3.

4. Gessford AK, John M, Nicholson B, et al. Marijuana induced hyperemesis: a case report. $W V$ Med 7 2012; 108(6):20-2.

5. Iacopetti CL, Packer CD. Cannabinoid hyperemesis syndrome: a case report and review of pathophysiology. Clin Med Res 2014;12(1-2):65-7.

6. Patterson DA, Smith E, Monahan M, et al. Cannabinoid hyperemesis and compulsive bathing: a case series and paradoxical pathophysiological explanation. 7 Am Board Fam Med 2010;23(6):790-3.

7. Simonetto DA, Oxentenko AS, Herman ML, et al. Cannabinoid hyperemesis: a case series of 98 patients. Mayo Clin Proc 2012;87(2):114-9.

8. Sofka S, Lerfald N. Cannabinoid hyperemesis syndrome: a case series. $W V$ Med 7 2013;109(3):20-3.

9. Soriano-Co M, Batke M, Cappell MS. The cannabis hyperemesis syndrome characterized by persistent nausea and vomiting, abdominal pain, and compulsive bathing associated with chronic marijuana use: a report of eight cases in the United States. Dig Dis Sci 2010;55(11):3113-9.

10. Makkar J. Medical marijuana update: summary of regulations; new role for physicians and possible concerns. Ont Med Rev 2014:17-9.

11. Juurlink DN. Medicinal cannabis: time to lighten up? $C M A \mathcal{F}$ 2014;186(12):897-8

12. Kahan $M$, Srivastava A. New medical marijuana regulations: the coming storm. CMAJ 2014;186(12):895-6.

13. Owens B. Quebec doctors aim to fill marijuana knowledge gaps. CMA7 2014;186(9):657.

14. Owens B. Colleges set guidelines for marijuana. CMA7 2014;186(9):E315.

15. Galli JA, Sawaya RA, Friedenberg FK. Cannabinoid hyperemesis syndrome. Curr Drug Abuse Rev 2011;4(4):241-9.

16. Sannarangappa V, Tan C. Cannabinoid hyperemesis. Intern Med 7 2009;39(11):777-8.

17. Sullivan S. Cannabinoid hyperemesis. Can 7 Gastroenterol 2010;24(5):284-5. 
18. Wallace EA, Andrews SE, Garmany CL, et al. Cannabinoid hyperemesis syndrome: literature review and proposed diagnosis and treatment algorithm. South Med f 2011;104(9):659-64.

19. Habboushe J, Sedor J. Cannabinoid hyperemesis acute renal failure: a common sequela of cannabinoid hyperemesis syndrome. Am 7 Emerg Med 2014;32(6):690-2.

20. Gilbert EH, Lowenstein SR, Koziol-McLain J, et al. Chart reviews in emergency medicine research: where are the methods? Ann Emerg Med 1996;27(3):305-8.

21. Worster A, Haines T. Advanced statistics: understanding medical record review (MRR) studies. Acad Emerg Med 2004;11(2):187-92.

22. Worster A, Bledsoe RD, Cleve $\mathrm{P}$, et al. Reassessing the methods of medical record review studies in emergency medicine research. Ann Emerg Med 2005;45(4):448-51.

23. Sorensen C, DeSanto K, Borgelt L, et al. Cannabinoid hyperemesis syndrome: diagnosis, pathophysiology, and treatment - a systematic review. 7 Med Toxicol 2017;13:71-87.

24. Allen JH, de Moore GM, Heddle R, et al. Cannabinoid hyperemesis: cyclical hyperemesis in association with chronic cannabis abuse. Gut 2004;53(11):1566-70.
25. Donnino MW, Cocchi MN, Miller J, et al. Cannabinoid hyperemesis: a case series. 7 Emerg Med 2011;40(4): e63-6.

26. Kim HS, Anderson JD, Saghafi O, et al. Cyclic vomiting presentations following marijuana liberalization in Colorado. Acad Emerg Med 2015;22(6):694-9.

27. Ruffle JK, Bajgoric S, Samra K, et al. Cannabinoid hyperemesis syndrome: an important differential diagnosis of persistent unexplained vomiting. Eur 7 Gastroenterol Hepatol 2015;27(12):1403-8.

28. Tack J, Talley NJ, Camilleri $M$, et al. Functional gastroduodenal disorders. Gastroenterology 2006;130(5): 1466-79.

29. Rotermann M, Langlois K. Prevalence and correlates of marijuana use in Canada. Health Rep 2015;26(4):10-5.

30. Hickey JL, Witsil JC, Mycyk MB. Haloperidol for treatment of cannabinoid hyperemesis syndrome. Am 7 Emerg Med 2013;31(6):1003-6.

31. Lucas J, Batt RJ, Soremekun OA. Setting wait times to achieve targeted left-without-being-seen rates. Am 7 Emerg Med 2014;32(4):342-5. 